\title{
Taxonomic, biogeographic, and taphonomic reassessment of a large extinct species of paca from the Quaternary of Brazil
}

Elver Luiz Mayer, Alex Hubbe, Leonardo Kerber, Paulo Miguel Haddad-Martim, and Walter Neves Acta Palaeontologica Polonica 61 (4), 2016: $743-758$ doi:http://dx.doi.org/10.4202/app.00236.2015

The taxonomy of extinct species of Cuniculus (Caviomorpha, Rodentia, Mammalia) is confusing and poorly studied. Here we provide a taxonomic review of extinct cuniculids, and discuss the taxonomic, biogeographic, taphonomic and chronologic aspects of new remains of an extinct large cuniculid from Brazilian Quaternary Gruta Cuvieri cave deposits. Our taxonomic review suggests that Cuniculus rugiceps (Lund, 1837) is the valid taxon to include all available occurrences of extinct cuniculids. The most evident features of this taxon are its larger size and the stronger and more densely distributed rugosities on the skull external surface when compared to the extant species. At present, the distribution of $C$. rugiceps is restricted to the tropical region of Brazil. Regarding the new remains, taphonomic analysis of the specimens from Cuvieri Cave suggests our sample is represented by at least seven individuals that accumulated within the cave deposit by pitfall entrapment. The biostratinomy of the specimens was characterized by prolonged surface exposure inside the pit with fragmentation and displacement caused mostly by falling and subsequent trampling by individuals of the same and/or other species. The stratigraphically controlled excavations and chronological data allowed the establishment of a Late Pleistocene minimum age for these specimens.

Key words: Mammalia, Rodentia, Caviomorpha, Cuniculidae, cave environments, karst, Pleistocene, Lagoa Santa.

Elver Luiz Mayer [elvermayer@gmail.com], Programa de Pós-Graduação em Geociências, Universidade Federal do Rio Grande do Sul, Av. Bento Gonçalves 9500, Porto Alegre, RS 91501-970, Brazil; Laboratório de Estudos Evolutivos Humanos, Departamento de Genética e Biologia Evolutiva, Instituto de Biociências, Universidade de São Paulo, Rua do Matão 277, São Paulo, SP 05508-090, Brazil. Alex Hubbe [alexhubbe@yahoo.com], Departamento de Oceanografia, Instituto de Geociências, Universidade Federal da Bahia, Salvador, BA 40170-020, Brazil; Instituto do Carste. Rua Barcelona, 240/302, Belo Horizonte, MG 30360-260, Brazil. Leonardo Kerber [leonardokerber@gmail.com ], CAPPA-Centro de Apoio à Pesquisa Paleontológica da Quarta Colônia, Universidade Federal de Santa Maria, Rua Maximiliano Vizzotto 598, São João do Polêsine, RS 97230-000, Brazil. Paulo Miguel Haddad-Martim [pmiguelhm@ gmail.com 
] and Walter Neves [waneves@ib.usp.br], Laboratório de Estudos Evolutivos Humanos, Departamento de Genética e Biologia Evolutiva, Instituto de Biociências, Universidade de São Paulo, Rua do Matão 277, São Paulo, SP 05508-090, Brazil.

This is an open-access article distributed under the terms of the Creative Commons Attribution License (for details please see creativecommons.org), which permits unrestricted use, distribution, and reproduction in any medium, provided the original author and source are credited.

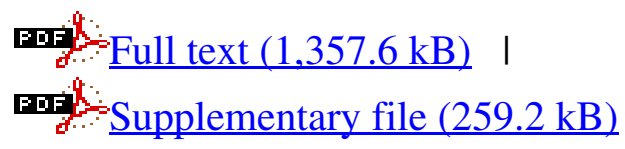

